\title{
FORUM
}

\section{The Myth of the Sacred Calabash}

\author{
P. Richards-Jones
}

During my days of 'tramping' across the Pacific Ocean as an apprentice, I had heard vague references to the effect that the Polynesians used coconut shells as an aid to navigation. Intrigued as I was, the opportunity never presented itself for me to pursue the matter further until years later, by which time I knew that I was in search of the 'Sacred Calabash'.

Examining some correspondence at a museum, I came across the first piece of non-evidence-a flat denial. I quote from the letter: 'As regards the sacred calabash of the Pacific, that I am afraid, is a myth and there never was anything of the sort. That yarn was started in good faith by a well-known American Admiral and, owing largely to his well deserved position in his profession, was accepted for a long time without any doubt, but recently it has been found to be quite false. They had no "magic coconuts" to help them'.

Far from feeling despondent over this, it only served to spur me on to research more, for so far I still had no idea what the calabash was, or how it was supposed to work. Eventually I found the Admiral's name and his book; an extract from it follows which describes the calabash and how it was used:

'Now, as to the Calabash itself, it is more or less cylindrical or slightly keg shaped, made of native Koa Wood and so far as 1 can remember was about 18 inches in height. It might be likened to a keg with the head removed. Within a few inches of the top, four holes had been bored, spaced 90 degrees apart and on a circle whose plane was at right angles to the horizontal axis or on one of the upper hoops of the keg.

As they gained latitude to the northward, the calabash was filled with water up to the holes. Through any one of these holes and over the opposite rim of the calabash, observations were made on the North Star until still observing through the holes, it became a tangent to the upper rim. When the condition was obtained, the course was immediately changed to Westward and could then be altered from time to time if necessary, so that Polaris would remain approximately a tangent. This would ensure their keeping in the approximate latitude of Hawaii and arrival at that island in due course of time.'2

The principle, of course, is that of finding the latitude by the altitude of the Pole Star and the same desired effect could be obtained by fixing the distance on a cross staff, or, for that matter, fixing a sextant at a desired altitude.

Admiral Hugh Rodman, U.S.N., states that he was able to obtain permission and put the calabash, which was then a museum piece, to the test. The water, acting as a level, kept the calabash vertical and when sighted the Pole Star rested on the rim, thus coinciding with the latitude of $19^{\circ}$. This he thought justified its use as an instrument of navigation and as it is based on the principle of the older type of European instruments, e.g. quadrant, forestaff, astrolabe, Arab 
kamal, \&c., it was difficult to believe that it did not exist or that such a device was not used, especially as the water level could be said to act as an artificial horizon.

Admiral Rodman wrote that the specimen he had tried resided at the Bishop Museum of Hawaii. However, although there is such a specimen there, it is not an instrument of navigation and neither is it described as such. It is a container for valuable possessions, or in other words, a watertight suitcase to use on long voyages. It has, indeed, a series of holes around the rim and they are in threes, but their distance from the edge is such that sighting through even the lowest of the three holes would only give an angle of $\mathrm{I}^{\circ}$ or thereabouts. In no case do the holes give an angle anywhere near $20^{\circ}$. Moreover, the height of the calabash is some 33 inches, with perhaps a 2 inch diameter. Filled with water to the hole level would give a weight of water near to $100 \mathrm{lb}$. It might seem then that to hold this weight at chest level, in a bobbing canoe, would present a gargantuan task.

There are, in fact, other similar calabashes (at the Bernice Bishop Museum) which indicate that the use of the holes was probably for threading the lashings through when tying the top on.

It would appear therefore that the 'sacred calabash sextant' is unfortunately a myth and the Polynesians did not, after all, navigate by coconut shells. Fortunately, the sticks of the Marshall Islanders are still with us.

1 E. de Bisschop, Tahiti Nul.

REFEREN CES

2 Admiral Hugh Rodman, U.S.N., Yarns of a Kentucky Admiral.

Correspondence research: Bernice Bishop Museum; University of Hawaii Museum; National Maritime Museum, Honolulu.

\title{
Accuracy Contours for Horizontal Angle Position Lines
}

\author{
E. M. Goodwin and J. F. Kemp \\ (City of London Polytechnic)
}

THIs paper describes a method of constructing accuracy contours for a position line obtained by observing the horizontal angle between two stations. An example is given using an estimate made, from experimental evidence, of the observational errors that are likely to occur when such angles are measured by sextant. A recent paper by Cotter ${ }^{1}$ described the historical development of this method of obtaining a position line.

In principle, the observed horizontal angle $(\theta)$ defines a position line which is the locus of a point that moves so that the angle at the point subtended by the baseline between the two stations is constant. Such a position line is the arc of a circle which passes through the two stations. Its centre may be found since it lies on the perpendicular bisector of the baseline, and the angle at the centre subtended by the baseline is twice the observed angle (Fig. I). 